\title{
Problems and Countermeasures of Working Capital Management in Company V
}

\author{
Yunjie Liu* \\ Zibo Vocational Institute, Zibo 255300, China \\ *Corresponding author: Yunjie Liu, workhardergirl@163.com
}

\begin{abstract}
Working capital is the premise for the production and operation of an enterprise and the basis for all financial management. The management of working capital has gained more attention by enterprises. The purpose of emphasizing the importance of working capital management is to enable enterprises to make full and efficient use of capital. There is a serious shortage of working capital in China's home appliance manufacturing industry, and with the rapid development of home appliance manufacturing industry, the problem is becoming increasingly prominent. Therefore, improving the management level of working capital, optimizing the structure of capital, and improving the efficiency of working capital should become the most important part in the process of daily production and operation. This article selects company $\mathrm{V}$ as the research subject as it has representative problems in working capital management. Drawing on the theoretical method of taking elements as the core, this article focuses on the analysis of each working capital project and the development status of the company as a whole, determines the problems in the aspects of current assets and information communication in regard to the working capital management of company $\mathrm{V}$, as well as puts forward several suggestions in terms of current assets management. In order to improve the working capital management level of company $\mathrm{V}$, we hope that the improvement suggestions derived from the combination of theory and practical analysis can provide some reference for other enterprises in the household appliance manufacturing industry.
\end{abstract}

Keywords: Working capital management; Household appliance manufacturing enterprise

Publication date: September 2021; Online publication: September 30, 2021

\section{Introduction}

The scope of working capital management mainly includes the management of current assets and current liabilities of enterprises. Therefore, in the management process of working capital, the use of funds and fund-raising are the core aspects that need to be focused on ${ }^{[1]}[1]$. The common question is how much capital enterprises should invest in the current assets and how to carry out financing activities of the current assets in the market. Working capital has become the most active capital for enterprises because of its short turnover period, strong liquidity, and low financial risk. It always plays a role in the production and operation of enterprises. Efficient management of working capital is the basis to ensure the orderly progress of various processes in an enterprise. At the same time, working capital is the most dynamic and the most liquid part in the capital structure of an enterprise. Therefore, excellent working capital management can release the most dynamic and creative energy in the capital structure of an enterprise and assist the rapid development of an enterprise to a great extent.

\section{Problems of the working capital management in company $\mathbf{V}$}

The products of company V mainly include air conditioners, refrigerators, washing machines, and other household appliances, which are sold overseas. Its main business includes research and development 
(R\&D), manufacturing, marketing, and after-sales service of household appliances, such as air conditioners, refrigerators, and washing machines.

\subsection{Low current assets management efficiency and poor idle monetary funds management}

In recent years, the amount of monetary capital of company $\mathrm{V}$ and its proportion in short-term operating assets are gradually increasing. The company has retained a large amount of monetary capital, which has not been used for paying goods or investing in marketable securities with high rate of return in time ${ }^{[2]}$. Moreover, the short-term operating assets of company $\mathrm{V}$ showed an increasing trend year by year. A large number of short-term operating assets would result in a high opportunity cost for the company. All the above phenomena indicate that company $\mathrm{V}$ has poor management of idle monetary funds and chooses to deposit a large amount of monetary funds in the bank, which has a very low interest income. Moreover, because it has not been put into production and operation, it is difficult for the company to realize the expansion of its business scale ${ }^{[3]}$.

\subsection{Low efficiency and high inventory management risk}

The proportion of goods in stock is the largest among all items of the company's inventory. On the whole, the goods in stock showed an upward trend year by year. A large number of reserved goods does not only imply high storage costs, but also may increase the company's sales burden. Once sales failure occurs, the liquidity of a large number of inventories would be seriously damaged, or even permanently overstocked in the warehouse. Secondly, the time management of company V's inventory is unreasonable. Company V is a household appliance manufacturer. According to the traditional custom of buying all kinds of products at the end of the year for a new year, people tend to replace old household appliances in January and February. Therefore, the end of each year is the time for household appliances promotion. Company V's inventory did not significantly increase at the end of each year, but the inventory in March of the following year increased significantly compared to the beginning of the year. This shows that the timing of company V's selection of inventory is not logical, and the timing of sales promotion is also not well grasped; thus, the sales situation during New Year's festival could not achieve satisfactory results. Therefore, it can be appreciated that the inventory management risk of company $\mathrm{V}$ is high.

\subsection{Weak working capital management information communication}

The information is not delivered in time. Information has a strong timeliness for an enterprise. For example, the financial department of company $\mathrm{V}$ was not able to gather comprehensive information about purchasing, production, and sales in time. It is difficult to judge whether the fund plan has kept up with the market, whether the use of funds is efficient, or whether the fund plan needs to be adjusted according to the information. The surplus of raw materials and other things would occupy the capital, solidifying it and the capital turnover would be difficult. In that way, it cannot be used for production and operation activities or investment activities of the enterprise; thus, unable to contribute to the development of the enterprise.

The real-time sales data and other information obtained by the front-line sales department of company $\mathrm{V}$ about the market, customers, and competitors did not reach the production workshop and decisionmaking departments in time. Taking the production workshop as an example, if such information lags behind, the production workshop department would not be able to arrange a reasonable production plan for the machines and may produce excessive products. As a result, the overstocking of products, which do not only lead to the capital being occupied, but also the subsequent storage cost of inventory, cost of damage, and the loss of obsolete inventory due to the change of technology and market demand, would reduce the efficiency of the overall working capital management of the enterprise. 


\section{Countermeasures to improve the working capital management in company $\mathbf{V}$}

\subsection{Improving the management level of the employees}

The problems in company V's working capital management system are largely due to the management's inability to keep up with the pace of social and corporate development in the management's working capital management concepts and capabilities. Therefore, the management should focus on its working capital management and improve its management capabilities. On the one hand, the company should strengthen the awareness of working capital management. The awareness can influence the management and in turn, improve the subjective initiative of this type of ability. It is recommended that the management systematically learn the relevant theoretical knowledge of working capital management and concentrate on more scientific as well as modern companies with working capital management. After visiting and learning, only by seeing that it can be used in practice more reasonably and efficiently, the management can then have a better determination to change. At the same time, a good example can also provide the management some experience in order to improve their working capital management capabilities. On the other hand, the company should regularly organize specialized trainings and internal simulation investment competitions as well as link salaries to investment levels in order to enhance the overall working capabilities of the company's dedicated investment personnel, mobilize their initiative, thereby, improving their own level, and increase the number of internal investment personnel. Competitiveness increases the possibility of finding high-quality investment projects.

\subsection{Establishing a scientific procurement mechanism and improving the inventory classification management system}

It is recommended that company $\mathrm{V}$ should establish a reasonable inventory procurement mechanism and improve the status quo of excessive inventory hoarding so that its inventory can achieve a favorable condition, thereby reducing the company's capital occupation on inventory as well as the overall costs. The first is to conduct professional training for the existing procurement team to strengthen the procurement business level of the members so as to improve the efficiency of the company's use of funds in the procurement process. The second is to set up a special procurement supervision department to monitor the raw materials and production equipment purchased by the procurement department. The purchase order and physical objects should be supervised in order to ensure the effectiveness from the implementation of the purchase plan and to improve the confusion of the unclear power division in the procurement process. By formulating a scientific and effective procurement plan, the procurement team can ensure that the raw materials and packaging required by each production workshop based on big data materials, etc. are classified and refined, and each information in the procurement process is incorporated into a unified procurement management system. For example, procurement applications, orders, incoming inspections, procurement returns, finished product quality inspections, and other information can be summarized. In the system, the procurement-related information is analyzed and dispatched uniformly to achieve real-time tracking and control of procurement behavior. Finally, attention should be paid to the loss of raw materials caused by the transportation environment and distance while reasonable transportation methods should be used to reduce the cost of procurement and transportation. Unnecessary waste of purchased goods reduces transportation costs ${ }^{[4]}$.

\subsection{Improving the working capital management performance evaluation system}

The first is to formulate an inspection method for the current ratio and quick ratio. These two indicators are important indicators that are widely used to measure the company's solvency. These indicators are the key considerations for suppliers and customers when they decide on cooperative transactions with company V. 
As the development of the capital market approaches maturity, investment methods have become diversified. Strengthening the assessment of these indicators allows companies to clarify their solvency and liquidity capabilities, as well as effectively control the risks of capital management. In addition, it would also help enterprises to conduct production and business activities more stably, especially when facing risks. Therefore, company $\mathrm{V}$ should be more cautious about investment projects with higher returns and try to warrant rational and scientific investment activities.

The second is to give full play to the role of current ratio and quick ratio in identifying and controlling risks. Company $\mathrm{V}$ should take the current ratio and quick ratio into consideration when monitoring the safety of funds, as well as track the changes of these two indicators and the trend of a period at any time according to the company's different development stages and market environment backgrounds ${ }^{[5]}$. Under the operating conditions of the capital, there should be a comprehensive consideration of the different levels of liquidity and security impact on the company using the analyzed data as an important basis for decisionmaking in order to avoid the company's capital chain from being broken due to insufficient consideration of risks.

\subsection{Building a complete information management system}

\subsubsection{Improving the standardization of the information system}

It is recommended that company $\mathrm{V}$ should pay attention to the use of information system based on the characteristics of its own production and operation, use the advanced technology on the market to update the software of the information system, as well as encourage and promote the genuine information management system within the company. The security of information related to the company's major production and operation should be paid special attention, such as the strict approval of off-site information backup as well as the setting and maintenance of system firewalls, in order to reduce the damage of such risks to the company and to allow information management. The system provides a strong guarantee for the company's working capital management ${ }^{[6]}$.

\subsubsection{Paying attention to and excelling in information collection}

For company V, the enterprise resource planning (ERP) system can effectively solve the company's existing working capital management and processing methods that are not scientific and reasonable. The Art of War states, "If you know the enemy and know yourself, you need not fear the result of a hundred battles." Therefore, in order for company $\mathrm{V}$ to surpass its competitors as quickly as possible and to occupy a more important position in the market, it is necessary to have a clear and reasonable understanding of its own development status because most of the information needed by the "confidant" is from the inside of the company; this is generally easier than "knowing the enemy." "Knowing the enemy" means collecting as much information as possible from competitors, especially those who are stronger, in order to understand the opponents' current and future plans, current market dynamics and information system, quality of software suppliers, etc. These preliminary efforts must be done solidly as they are the cornerstone of building a complete information system. Only after combining the aforementioned can the company choose a suitable software supplier, laying the foundation for subsequent software system adjustment.

\subsubsection{Developing a master plan for the implementation of the information system}

The ERP system is based on modern network conditions, specifically through relevant computer software and software management systems required by business tools, to help companies improve the processing capabilities of the management process of each production and operation activity link without the need to distinguish between production and logistics any longer, but to carry out a scientific integration of the two 
and also incorporate financial as well as other information into a system, forming a more comprehensive internal management system, thus making the internal management of the enterprise more organized and clearer while strengthening the internal and external aspects of the company. The flow of funds helps corporate decision makers to have a more comprehensive perspective on the issues they see and consider when formulating a company's plan. Therefore, in order for a company to efficiently conduct information management, not only a proper information system management software is required, but also an overall plan.

\section{Enlightenment}

Through the research on the problems, causes, and countermeasures of the working capital management in company $\mathrm{V}$, which is a representative household appliance manufacturer, there is enlightenment for the whole household appliance manufacturing industry.

First, the management is the decision maker of business operations and the ultimate operator of working capital management. Therefore, the management should attach importance to and strengthen the ability to manage working capital, in addition to always maintain advanced and scientific working capital management concepts. Second, a sound working capital management system and information management system as well as sufficient technical support can theoretically improve and enhance the environment for implementation. Third, working capital is a large category, including multiple current assets and small categories of current liabilities. Different projects have their own specific management methods and promotion methods, which cannot be merely assumed without distinction ${ }^{[7]}$. Each enterprise in the industry needs to make scientific and effective solutions based on its own conditions.

\section{Conclusion}

Working capital management plays an important role in enterprise management as well as in the production and operation activities of an enterprise, directly affecting the profitability of an enterprise. The close relationship between working capital management and profitability is mainly due to the fact that capital is the premise of a business to operate normally and only with funds, raw material production products can be purchased. The excellence of working capital management is determined by enterprises' management ability. Excellent working capital management ability can promote better and faster development of enterprises, whereas poor working capital management ability would hinder the benign development of enterprises and might even bring devastating impact to these enterprises. Therefore, enterprises should pay attention to the management of working capital and take it as the focus of financial management, especially the financial departments, which are directly related to working capital. Moreover, other than rapid changes, working capital management has strong liquidity and turnover. Therefore, the enterprises' methods of working capital management should keep up with the changes. In addition, the status of their working capital management should be analyzed in real time and a working capital management strategy should be formulated in line with the enterprises' actual situation.

\section{Disclosure statement}

The author declares that there is no conflict of interest.

\section{References}

[1] Lin X, 2010, Analysis of Enterprise Working Capital Management Strategy. China Business, (196): 12-14. 
[2] He H, 2011, Risks and Countermeasures of Working Capital Management. Beifang Economic and Trade Journal, (3): 84-85.

[3] Wang Y, Wang Z, Sun Y, et al., 2017, Survey on Capital Efficiency and Financial Risk of Listed Companies in China: 2016. Accounting Research, (12): 66-72, 97.

[4] Wang Z, Wang Z, Li J, 2017, Business Risk and Working Capital Financing Decision. Accounting Research, (05): 62-69, 99.

[5] Zhang X, Yu Y, 2017, Research on the Performance Improvement Strategy of Working Capital Management of Gree Electric Appliances - Based on the Comparative Analysis with Qingdao Haier. Friends of Accounting, (02): 47-5.

[6] Chen Z, 2015, Problems in Enterprise Capital Management and Effective Control Measures. China Market, (13): 37-38.

[7] Sun J, 2016, Current Situation, Problems and Countermeasures of Working Capital Management of Small and Medium Sized Enterprises in China. Accounting Research, (16): 8-9. 